\title{
MEMBANGUN BUDAYA MENCIPTA DAN KREATIVITAS KERJA KARYAWAN PADA INDUSTRI KREATIF DI PROVINSI BANTEN
}

\author{
Aan Khurosani \\ Jurusan Manajemen, Fakultas Ekonomi dan Bisnis, Universitas Sultan Ageng Tirtayasa, Indonesia \\ *Email corresponding author: aankhurosani@untirta.ac.id \\ Diterima 27/08/2020 Direvisi 20/09/2020 Diterbitkan 30/09/2020
}

\begin{abstract}
Abstrak
Industri kreatif adalah sektor yang potensial untuk pengembangan industri kecil dan menengah di Indonesia. Industri ini fokus menciptakan barang dan jasa yang mengandalkan keahlian, bakat dan kreativitas sebagai kekayaan intelektual. Tujuan penelitian ini adalah untuk menganalisis pengaruh budaya mencipta, perilaku kebebasan berkreasi dan kesediaan membuka jaringan terhadap kreativitas kerja karyawan pada industri kreatif di Provinsi Banten. Sampel diambil dengan menggunakan teknik Purposive Sampling sejumlah 95 responden. Analisis data menggunakan analisis Structural Equation Modeling dengan program PLS 3.0. Hasil penelitian menunjukkan bahwa tidak terdapat pengaruh budaya mencipta terhadap kreativitas kerja karyawan. Terdapat pengaruh positif dan signifikan budaya mencipta terhadap perilaku kebebasan berkreasi, terdapat pengaruh positif dan signifikan perilaku kebebasan berkreasi terhadap kreativitas kerja karyawan, terdapat pengaruh positif dan signifikan perilaku kebebasan mencipta terhadap kesediaan membuka jaringan dan terdapat pengaruh yang positif kesediaan membuka jaringan terhadap kreativitas kerja karyawan.

Kata Kunci:Budaya Mencipta, Perilaku Kebebasan Berkreasi, Kesediaan Membuka Jaringan, Kreativitas Kerja.
\end{abstract}

\begin{abstract}
Creative industry is a very potential sector in the development of small and medium industries in Indonesia. Creative industries are industries that focus on creating goods and services by relying on expertise, talent and creativity as intellectual property. The purpose of this study was to analyze the influence of creating culture, freedom of creation behavior and willingness to open a network of employee work creativity in the creative industries in Banten Province. The sampling technique uses purposive sampling technique with a sample of 95 respondents. Data analysis using Structural Equation Modeling analysis with PLS 3.0 program. The results showed that there was no influence of creating culture on employee work creativity. There is a positive and significant influence of creating culture on freedom of creative behavior, there is a positive and significant influence on freedom of creation behavior on employee work c reativity, there is a positive and significant influence on creating freedom of behavior on the willingness to open networks and there is a positive influence on willingness to open networks on employee work creativity.
\end{abstract}

Key Words: Creating Culture, Freedom of Creative Behavior, Willingness to Open Networks, Work Creativity

\section{PENDAHULUAN}

Dalam rangka meningkatkan pertumbuhan ekonomi kreatif Indonesia saat ini terus menggalakan industri kreatif. Pemerintah mendorong industri kreatif sebagai sumber kekuatan ekonomi baru yang dikembangkan lebih lanjut di dalam perekonomian nasional. Pemerintah mendorong industri kreatif karena peluang pengembangan ekonomi kreatif dapat penciptaan 


\section{PERFORMANCE}

Jurnal Personalia, Financial, Operasional,

Marketing dau Sistem Informasi

Performance. Volume 27 Nomor 2 Tahun 2020, 49-61

lapangan kerja, membantu pengentasan kemiskinan, meningkatkan pendapatan nasional dan mampu menumbuhkan kecintaan terhadap bangsa dan negara (Fitriana, 2014).

Dalam industri kreatif, kreativitas merupakan faktor penting yang harus dimiliki oleh pemilik atau pengelola. Banyaknya industry kreatif yang kalah bersaing karena mereka kurang kreatif. Kreativitas sebagai faktor penting dalam menunjang keberhasilan dan keunggulan kompetitif organisasi (Yuan \& Woodman, 2010); (Çekmecelioğlu \& Günsel, 2013). Organisasi yang didukung teknologi akan lebih kreatif dan inovatif serta mampu bertahan hidup, bersaing, tumbuh, dan memimpin (Jung et al., 2003); (Tierney et al., 2014).

Kualitas dan inovasi kerja organisasi sangat erat jika dikaitkan dengan budaya organisasi (Ali Taha et al., 2016). Budaya organisasi dapat menjadi kunci untuk mendorong keberhasilan perusahaan. Meskipun sepenuhnya tidak sesuai, bahwa organisasi akan berhasil apabila mempunyai budaya yang kuat, tetapi organisasi yang berhasil bukan sekedar mempunyai budaya yang kuat melainkan mampu beradaptasi dengan lingkungannya (Mobarakeh, 2011).

Budaya organisasi terdiri dari empat jenis budaya dominan: hirarki, pasar, clan dan mencipta (Cameron, Kim S. \& Quinn, 2006); (Asbari et al., 2019). Budaya mencipta adalah budaya organisasi yang memberikan kesempatan lebih banyak bagi individu untuk mengembangkan dengan cara mereka sendiri, asalkan mereka konsisten dengan tujuan organisasi. Fokus organisasi adalah untuk mendapatkan peluang sebanyak mungkin dari lingkungan eksternal Individu akan dianggap sebagai orang-orang yang berhasil jika mereka dapat menciptakan dan mengembangkan ide-ide baru dan inovasi (Aktaş et al., 2011).

Namun demikian dalam penelitian sebelumnya hubungan antara budaya organisasi dan kreativitas / inovasi relatif terbatas(McLean, 2005), (Dubkēvičs et al., 2015). Oleh karena itu diperlukan sebuah perilaku yang memberikan kebebasan berkreasi kepada individu untuk mengekspresikan kemampuannya dalam mengeluarkan ide-ide atau gagasan baru sehingga memunculkan kreativitas dalam bekerja. Hal ini sesuai dengan penelitian (Gilson \& Litchfield, 2017) bahwa karyawan yang diberi kebebasan dalam menciptakan ide-ide atau gagasan akan memiliki keleluasaan untuk memikirkan apa yang akan diciptakannya.

Perilaku kebebasan berkreasi inipun akan dapat diciptakan melalui suatu nilai-nilai yang disepakati oleh organisasi dengan menerapkan budaya mencipta. Nilai budaya mencipta yang dibuat oleh organisasi akan memberikan kebebasan bagi karyawan untuk selalu berkreasi dalam membuat pemikiran-pemikiran dan kegiatan-kegiatan baru. Pernyatan ini sesuai dengan penelitian (Aktaş et al., 2011) bahwa budaya adhocracy adalah budaya organisasi yang memberikan kesempatan lebih banyak bagi individu untuk mengembangkan dengan cara mereka sendiri, asalkan mereka konsisten dengan tujuan organisasi.

Selanjutnya perilaku kebebasan berkreasi akan mempunyai makna apabila setiap individu melakukan pembelajaran yang secara terus menerus. Perilaku kebebasan berkreasi yang dimiliki individu akan selalu mencari referensi-referensi dan selalu belajar untuk mencari hal-hal yang baru. Oleh karena itu semakin tinggi perilaku kebebasan berkreasi maka akan semakin tinggi keinginan untuk membuka jaringan. Pernyataan ini sejalan dengan hasil penelitian (Ogbeibu et al., 2018) yang menunjukkan bahwa budaya mencipta mendorong kebebasan dan mengambil inisiatif sebagai sumber nilai kompetitif. Perilaku individu yang ingin maju selalu bersedia untuk belajar dengan membuka jaringan. Kesediaan membuka jaringan merupakan bagian dari berbagi pengetahuan. Berbagi pengetahuan dapat dikonseptualisasikan dalam berbagai cara mulai dari eksplorasi pengetahuan baru melalui kombinasi baru dari pengetahuan yang ada (Uzzi et al., 2007), (Karlsson, 2011). Karyawan yang bersedia membuka jaringan akan memperoleh manfaat berupa ilmu pengetahun dan pengalaman yang pada akhirnya akan meningkatkan kreativitas kerjanya. Ungkapan ini sesuai dengan penelitian (Rashid \& Rahman, 2014) bahwa penggunaan situs jejaring sosial akan meningkatkan kreativitas siswa. Dalam kontek industri kreatif, perilaku 


\section{PERFORMANCE}

Jurnal Personalia, Financial, Operasional,

Marketing dau Sistem Informasi

Performance. Volume 27 Nomor 2 Tahun 2020, 49-61

kebebasan berkreasi merupakan serangkaian kegiatan dengan dimensi generasi ide, promosi ide, dan realisasi ide dengan teknologi, proses, teknik, atau produk baru (Yuan \& Woodman, 2010).

Budaya mencipta dibangun dengan dimensi kemampuan beradaptasi, fleksibilitas, berinovasi, menciptakan standar baru, perbaikan terus-menerus, dan kreatif mencari solusi (Jung et al., 2003), (Khurosani, 2013). Kesediaan membuka jaringan didukung oleh dimensi teknologi informasi, jaringan pribadi, teknik berbagi pengetahuan, memiliki team work (Kelompok Kerja), berbagi pengetahuan secara bebas (Karlsson, 2011). Kreativitas kerja karyawan ditandai oleh dimensi kemampuan untuk menciptakan, mewujudkan, menciptakan ke dalam bentuk baru, menghasilkan melalui keterampilan imajinatif, dan untuk menjadikan ada sesuatu yang baru (Chen \& Lin, 2010). Penelitian ini secara eksplisit meneliti pengaruh budaya mencipta terhadap kreativitas kerja karyawan melalui variabel intervening perilaku kebebasan berkreasi dan kesediaan membuka jaringan pada industri kreatif di Provinsi Banten. Penelitian ini sangat relevan dilakukan pada Industri kreatif di Provinsi Banten, agar pelaku industri kreatif dapat mendorong kreativitas kerja karyawan dengan nilai budaya mencipta, perilaku kebebasan berkreasi,dan kesediaan membuka jaringan sehingga diharapkan akan mampu bersaing dalam memasarkan produknya.

\section{TINJAUAN PUSTAKA DAN PERUMUSAN HIPOTESIS}

\section{Budaya Mencipta}

Budaya mencipta, juga disebut sebagai budaya dan perkembangan kewirausahaan, yaitu gabungan budaya yang fokus pada tingkat fleksibilitas yang tinggi dengan penekanan pada posisi kompetitif, dimana budaya organisasi didukung oleh sistem terbuka yang mempromosikan kesediaan untuk bertindak (Schein, 2010), (Mobarakeh, 2011). Tujuan budaya mencipta adalah untuk mendorong kemampuan beradaptasi, fleksibilitas, dan kreativitas (Khurosani, 2013). Jenis budaya mencipta ditandai dengan menjadi dinamis dan inovatif.

Budaya mencipta juga mendorong kebebasan dan mengambil inisiatif sebagai sumber nilai kompetitif (Jung et al., 2003), (Ogbeibu et al., 2018) . Budaya mencipta telah menunjukkan keunggulannya dalam hal kinerja mengenai beberapa produk dalam lingkungan yang berbeda. Suasana kerja yang dinamis dan inovatif serta pemimpin yang baik kreatif dalam pengambilan resiko (Bai et al., 2016).

\section{Perilaku Kebebasan berkreasi}

Sebuah organisasi yang maju adalah organisasi yang memberikan kebebasan bagi setiap individu, dalam mengembangkan imajinasinya (Qi et al., 2019) untuk melahirkan sebuah hasil karya. Kegiatan individu tersebut dalam bekerja selalu menghasilkan hal-hal yang baru dan imajinatif (Gilson \& Litchfield, 2017). Perilaku kebebasan berkreasi dianggap sebagai serangkaian kegiatan yang berkaitan dengan generasi ide, promosi ide, dan realisasi ide dengan teknologi, proses, teknik, atau produk baru (Yuan \& Woodman, 2010). Perilaku kebebasan berkreasi fokus pada proses inovasi, (yaitu, terlibat dalam kegiatan inovatif) dan hasil inovasi (yaitu, produk baru) yang berada di luar konsep kreativitas (Zhiming et al., 2013). Untuk lebih mengembangkan perilaku kebebasan berkreasi, perlu adanya kebebasan mengeluarkan ide, dorongan pengawasan pimpinan, dan dukungan organisasi (Bammens, 2016).

Organisasi yang memberikan kebebasan berkreasi adalah organisasi yang menerapkan kepercayaan (trust) terhadap anggota organisasi dalam sistem budaya organisasinya (Mobarakeh, 2011). Kepercayaan interpersonal atau kepercayaan antara rekan kerja adalah atribut yang sangat penting dalam budaya organisasi, yang diyakini memiliki pengaruh kuat atas berbagi pengetahuan (Duran et al., 2016). 
Performance. Volume 27 Nomor 2 Tahun 2020, 49-61

\section{Kreativitas Kerja}

Kreativitas ditandai oleh kemampuan untuk menciptakan, mewujudkan, menciptakan ke dalam bentuk baru, menghasilkan melalui keterampilan imajinatif, sehingga menjadi sesuatu yang baru. Kreativitas tidak saja mampu untuk menciptakan dari ketiadaan, tetapi mampu untuk menghasilkan gagasan baru dengan mengganti dan menggabungkan serta mengubah, atau menerapkan kembali ide-ide yang ada (Harris \& Mossholder, 1996), (Chen \& Lin, 2010).

Kreativitas sebagai sikap, memiliki kemampuan untuk menerima perubahan dan kebaruan, serta menemukan ide dan berpandangan fleksibilitas terhadap kebiasaan. Kreativitas juga sebagai proses dimana orang kreatif bekerja keras dan terus menerus untuk memunculkan ide dan gagasan, selanjutnya membuat perubahan dan penyempurnaan karya (Bai et al., 2016), (Gilson \& Litchfield, 2017). Kreativitas karyawan adalah fenomena tingkat individu yang mencerminkan

produksi ide-ide kreatif, dibangun secara unik berdasarkan ide yang ada gies, dan menyarankan pendekatan baru untuk menciptakan solusi baru (Ogbeibu et al., 2018).

\section{Kesediaan Membuka Jaringan}

Jaringan adalah sekumpulan aktor dan sekumpulan ikatan yang mewakili beberapa hubungan, atau ketiadaannya, di antara para aktor (Brass et al., 2004). Dalam pengaturan organisasi, jaringan biasanya melibatkan kontak dengan berbagai kolega untuk tujuan saling menguntungkan (Linehan \& Scullion, 2008). Hal ini tergantung pada interaksi informal yang melibatkan bantuan, persuasi, dan koneksi ke orang-orang yang sudah memiliki pengaruh. Jaringan penting untuk menyelesaikan tugas, mendapatkan mobilitas ke atas, dan pengembangan pribadi dan profesional (Zhang \& Bartol, 2010), (Rashid \& Rahman, 2014).

Berbagai konfigurasi jaringan, seperti jaringan pemasok dan konsumen, jaringan lokal perusahaan, jaringan profesional dan semua jaringan pengetahuan dapat berkontribusi pada proses kreatif (Karlsson, 2011). Kesediaan membuka Jaringan adalah keinginan dari seorang individu untuk membuka akses yang biasanya melibatkan kontak dengan berbagai kolega untuk tujuan saling menguntungkan.

\section{Perumusan Hipotesis}

\section{Budaya Mencipta terhadap Kreativitas Kerja Karyawan}

Budaya organisasi sebagai sekumpulan nilai, aturan dan norma yang disepakati bersama dengan orang-orang yang ada dalam sebuah organisasi. (Schein, 2010). Aturan dan norma yang disepakati ini adalah sebagai pegangan dalam melaksanakan interaksi dalam sebuah organisasi (Chen \& Lin, 2010). Budaya mencipta yang dikembangkan disebuah organisasi akan menjadi sebuah nilai dan norma yang dijadikan sebagai acuan dalam melaksanakan pekerjaan (Khurosani, 2013). Proses pelaksanaan budaya mencipta lebih menekankan pada sistem yang terbuka dalam mempromosikan kesediaan untuk bertindak (Villar et al., 2014).

Dalam hal ini kesediaan untuk bertindak adalah keleluasan dalam mengeluarkan ide-ide atau gagasan baru. Kemampuan dalam menciptakan ide-ide baru merupakan wujud dari kreativitas seseorang (Mobarakeh, 2011). Budaya mencipta yang dijadikan sebagai sebuah habit dalam sebuah organisai akan memberikan kesempatan seseorang untuk mencipakan hal-hal baru (Dubkēvičs et al., 2015). Oleh karena itu sebuah organisasi yang menerapkan budaya mencipta dengan memberikan kesempatan kepada karyawan dalam berimajinasi akan meningkatkan kreativitas kerjanya. Berdasarkan penjelasan dan kajian literatur maka dapat dikembangkan hipotesis penelitian sebagai berikut:

H1: Semakin tinggi budaya mencipta maka semakin tinggi kreativitas kerja karyawan. 
Performance. Volume 27 Nomor 2 Tahun 2020, 49-61

\section{Budaya Mencipta terhadap Perilaku Kebebasan berkreasi}

Budaya organisasi merupakan cerminan dari semua faktor lingkungan internal dan budaya organisasi memainkan peran penting dalam menerapkan strategi (Dubkēvičs et al., 2015). Budaya organisasi mampu memainkan peranan dalam merubah perilaku anggota organisasi agar mematuhi aturan dan norma yang telah dibuat (Ali Taha et al., 2016). Budaya organisasi dalam bentuk budaya mencipta yang telah terbentuk dalam organisasi menjadi sebuah norma yang harus dilaksanakan oleh semua anggota organisasi.

Budaya mencipta memberikan keleluasaan bagi anggota organisasi untuk mengeluarkan pemikiran-pemikirannya dalam menciptakan kreasi yang baru (Yuan \& Woodman, 2010). Keleluasaan untuk menciptakan hal-hal baru yang dimiliki oleh setiap anggota organisasi (karyawan) tanpa adanya pembatasan dari organisasi merupakan wujud dari perilaku kebebasan dalam berkreasi. Perilaku kebebasan berkreasi ini terwujud karena organisasi menerapkan budaya mencipta untuk setiap anggota organisasi. Berdasarkan penjelasan dan kajian literatur maka dapat dikembangkan hipotesis penelitian sebagai berikut:

\section{$\mathrm{H} 2$ : Semakin tinggi budaya mencipta maka semakin tinggi perilaku kebebasan berkreasi.}

\section{Perilaku Kebebasan Berkreasi Terhadap Kesediaan Membuka Jaringan}

Perilaku kebebasan berkreasi yang diberikan oleh organisasi akan nampak apabila terjadi komunikasi dengan bawahan. Komunikasi di sini mengacu pada interaksi individu dengan individu lainnya. Interaksi individu sangat ditingkatkan dengan adanya jejaring sosial di tempat kerja. Bentuk komunikasi adalah fundamental dalam mendorong transfer pengetahuan (Smith \& Rupp, 2002), (Sigala \& Chalkiti, 2015). Sistem informasi akan memberi dampak pada berbagi pengetahuan. Sistem informasi yang digunakan merujuk kepada pengaturan orang, data dan proses untuk mendukung operasi sehari-hari, pemecahan masalah dan pengambilan keputusan dalam organisasi (Rashid \& Rahman, 2014).

Perilaku kebebasan berkreasi yang dimiliki oleh setiap individu dalam organisasi yang telah menciptakan berbagai ide dan gagasan, lambat laun akan kehilangan imajinasi. Ide atau gagasan yang dibuat hasilnya tidak berbeda dengan yang sudah ada. Untuk mendapatkan ide-ide atau gagasan-gagasan baru, individu harus mau belajar dan mencari referensi dari berbagai liteatur (Brass et al., 2004). Kesediaan membuka jaringan harus selalu dimiliki oleh individu yang memiliki perilaku kebebasan berkreasi. Oleh karena itu perilaku kekebasan berkreasi ini akan mendapatkan ide atau gagasan baru jika selalu memiliki keinginan untuk membuka jaringan. Berdasarkan penjelasan dan kajian literatur dapat dikembangkan hipotesis penelitian sebagai berikut :

H3 : Semakin tinggi perilaku kebebasan berkreasi maka semakin tinggi kesediaan membuka jaringan.

\section{Perilaku Kebebasan Berkreasi terhadap Kreativitas Kerja}

Perilaku kebebasan berkreasi merupakan sarana untuk meningkatkan kreativitas kerja. Nilai kebebasan yang dimiliki akan memudahkan karyawan dalam berkreasi untuk menciptakan ideide kreatif. Karyawan yang diberi kebebasan dalam menciptakan ide-ide atau gagasan akan memiliki keleluasaan untuk memikirkan apa yang akan diciptakannya (Gilson \& Litchfield, 2017). Perilaku karyawan yang diberikan keleluasaan dalam berkreasi, akan dengan mudah membuat model, atau desain-desain sehingga akan muncul hasil cipta yang terbaru. Peranan karyawan yang berperilaku kreatif sangat penting yang selalu membutuhkan hal-hal yang baru.

Kreativitas kerja karyawan tidak muncul dengan sendirinya dalam pola kerja yang dilakukan ditempat kerja. Perlunya sebuah perilaku kerja yang tidak selalu ada dalam tekanan, tetapi ada dalam sebuah keluasaan dalam berekspresi dan bereksperimen dalam mengeluarkan ide atau gagasan (Hung et al., 2011). Sebuah pekerjaan yang selalu ada dalam tekanan akan menghasilkan kinerja apa adanya, simpel dan monoton. Oleh karena itu diperlukannya perilaku kebebasan 


\section{PERFORMANCE}

Jurnal Personalia, Financial, Operasional,

Marketing dau Sistem Informasi

Performance. Volume 27 Nomor 2 Tahun 2020, 49-61

berkreasi bagi setiap karyawan, sehingga akan dihasilkan sebuah pemikiran-pemikiran baru dalam membuat hasil karya baik berupa produk tangibel maupun intagible (Asbari et al., 2019). Berdasarkan penjelasan dan kajian literatur maka dapat dikembangkan hipotesis penelitian sebagai berikut :

\section{H4 : Semakin tinggi kebebasan berkreasi maka semakin tinggi kreativitas kerja karyawan.}

\section{Kesediaan Membuka Jaringan terhadap Kreativitas Kerja Karyawan}

Jaringan dapat dihubungkan secara horizontal dengan menempatkan orang-orang dalam organisasi untuk melakukan kontak langsung satu sama lain (Rashid \& Rahman, 2014). Teori jaringan terbagai kedalam tiga bagian (Karlsson, 2011) : Pertama jaringan menggunakan teknologi komunikasi modern untuk memfasilitasi transfer informasi secara cepat karena jarak. Setelah terhubung ke jaringan, orang akan menerima informasi kemudian mereka mensintesis dan munculah informasi baru. Oleh karena itu dengan adanya jaringan akan membantu dalam berbagi dan menciptakan ide-ide baru.

Kedua, jaringan pribadi memainkan peran penting dalam transfer pengetahuan tacit, yang merupakan masukan penting dalam proses kreatif. Transfer pengetahuan tacit memerlukan tatap muka interaksi dalam waktu yang lebih lama, yang berarti bahwa jaringan pribadi memiliki keunggulan yang kuat ketika datang untuk melakukan transfer pengetahuan tacit. Ketiga, proses kreatif ditandai dengan manipulasi informasi, ide dan pengetahuan, tetapi karakteristik informasi, ide dan pengetahuan tersebut berbeda dari bentuk awalnya. Faktor ini secara tradisional memberikan manfaat bagi penggerak awal dalam proses kreatif. Berdasarkan penjelasan dan kajian literatur maka dapat dikembangkan hipotesis penelitian sebagai berikut :

\section{H5 : Semakin tinggi kesediaan membuka jaringan maka semakin tinggi kreativitas kerja karyawan.}

Untuk mendapatkan gambaran yang jelas dari empat konstruk hubungan tersebut, dapat dilihat dalam model teoritis berikut ini (gambar 1):

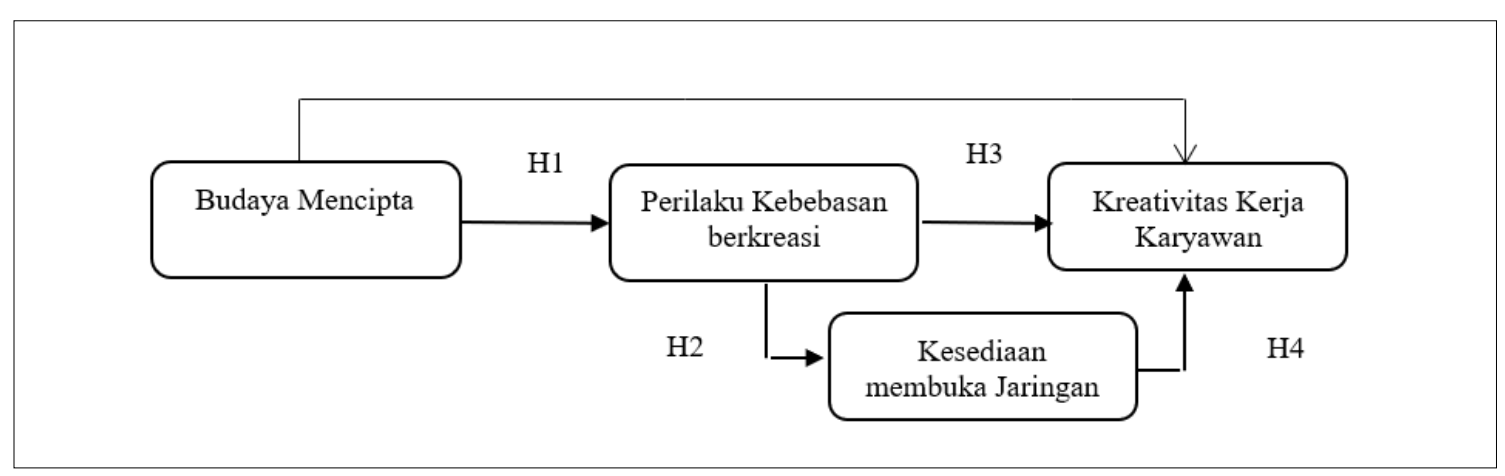

Gambar 1. Theoretical Model

\section{METODE PENELITIAN}

\section{Objek Penelitian dan Unit Analisis}

Objek yang diteliti adalah industri kreatif di Provinsi Banten, sedangkan unit analisis dari penelitian ini adalah karyawan yang bekerja di setiap industri kreatif. Penelitian ini menggunakan purposive sampling sebagai teknik pengambilan sampel. Hal ini dilakukan dengan mendistribusikan kuesioner terstruktur yang berisi pertanyaan tertutup dan terbuka. Pertanyaan tertutup menggunakan skala 1 hingga 10, di mana Skor 1 untuk Sangat Tidak Setuju dan Skor 10 untuk Sangat Setuju (Gorondutse \& Gawuna, 2017).

Selain pertanyaan tertutup, responden juga diberikan pertanyaan terbuka yang mewajibkan responden untuk memberikan jawaban dalam elaborasi, terutama untuk menguraikan hal-hal 


\section{PERFORMANCE}

Jurnal Personalia, Financial, Operasional,

Marketing dau Sistem Informasi

Performance. Volume 27 Nomor 2 Tahun 2020, 49-61

yang tidak dapat diungkapkan oleh pertanyaan tertutup (Peranginangin \& Kusumawardhani, 2018).

\section{Teknik Analisis dan Pengujian Model}

Jenis penelitian adalah penelitian kuantitatif. Teknik analisis penelitian adalah Structural Equation Model (SEM) yang didukung oleh perangkat lunak Partial Least Square (PLS) (Ghozali I, 2014), (Gorondutse \& Gawuna, 2017). Teknik analisis dilakukan dengan 2 (dua) tahap. Tahap pertama dengan melakukan evaluasi Measurement Model (Outer Model) yaitu melibatkan validitas konstruk dan reliabilitas konstruk.

Satu konstruk dianggap valid jika memiliki pemuatan standar $\geq 0,50$ dengan nilai Average Variance Extracted $(A V E) \geq 0,50$. Membangun reliabilitas dianggap baik jika memiliki nilai $\geq 0,70$ (Tabachnick dan Fidell, 2013). Tahap yang kedua dengan melakukan evaluasi Pengujian Model Struktural (Inner Model) yaitu menghitung nilai R-Square pada konstruk, menguji hipotesis dan menguji hubungan indirect effect.

\section{HASIL DAN PEMBAHASAN}

\section{Hasil Penelitian}

Ada seratus lima (105) kuesioner yang diberikan kepada responden. Dari kuesioner ini, diperoleh sembilan puluh lima (95) data responden dan kemudian diproses. Berdasarkan angkaangka ini, tingkat respons adalah $91 \%$. Terkait jenis kelamin, responden pria adalah $89 \%$ dari total atau 85 orang, sedangkan responden wanita adalah $11 \%$ atau 10 orang. Mengenai status perkawinan, responden yang menikah adalah $15 \%$ atau 14 orang, sedangkan responden belum menikah adalah $85 \%$ atau 81 orang. Sebagian besar responden lulus dari sekolah menengah, dan ditunjukkan oleh $77 \%$ dari total atau 73 orang, sedangkan sisanya memegang gelar akademik, yang diwakili oleh $23 \%$ dari total atau 22 orang.

\section{Evaluasi Measurement Model (Outer Model)}

Menurut Structural Equation Model (SEM-PLS) bahwa indikator dianggap baik jika memiliki tingkat pemuatan faktor $\geq 0,70$ atau serendah-rendahnya $\geq 0,70$. Laju pemuatan faktor dari sebagian besar indikator telah memenuhi kondisi ini. Validitas konstruk diukur menggunakan validitas konvergen dan pengukuran ini melibatkan perhitungan Average Variance Extracted. Reliabilitas konstruk diukur dengan mengkuadratkan laju pembebanan terstandarisasi dari masing-masing indikator variabel. Hasil perhitungan running pertama diperoleh hasil ouput ada 3 (tiga) indikator yang didrop out yaitu DBM5 dan 6, serta KMJ3 karena dibawah standar yang dipersyaratkan. Berikut ini hasil perhitungan pada running yang ke dua diperoleh hasil sebagai berikut:

Tabel 1. Convergent Validity and Construct Reliability

\begin{tabular}{clccc}
\hline No & Variabel/Indikator & $\begin{array}{c}\text { Std. Loading (Lamda } \\
\text { Value) }\end{array}$ & $\begin{array}{c}\text { Convergent } \\
\text { Validity (AVE) } \\
\geq 0.50\end{array}$ & $\begin{array}{c}\text { Construct } \\
\text { Reliability } \geq 0.70\end{array}$ \\
\hline 1 & Budaya Mencipta & 0,942 & & \\
& BM1 & 0,946 & 0,670 & 0,886 \\
& BM2 & 0,562 & & \\
& BM3 & 0,762 & & 0,905 \\
\hline 2 & BM4 & & 0,661 & \\
& Perilaku Kebebasan & & & \\
& Berkreasi & 0,540 & &
\end{tabular}




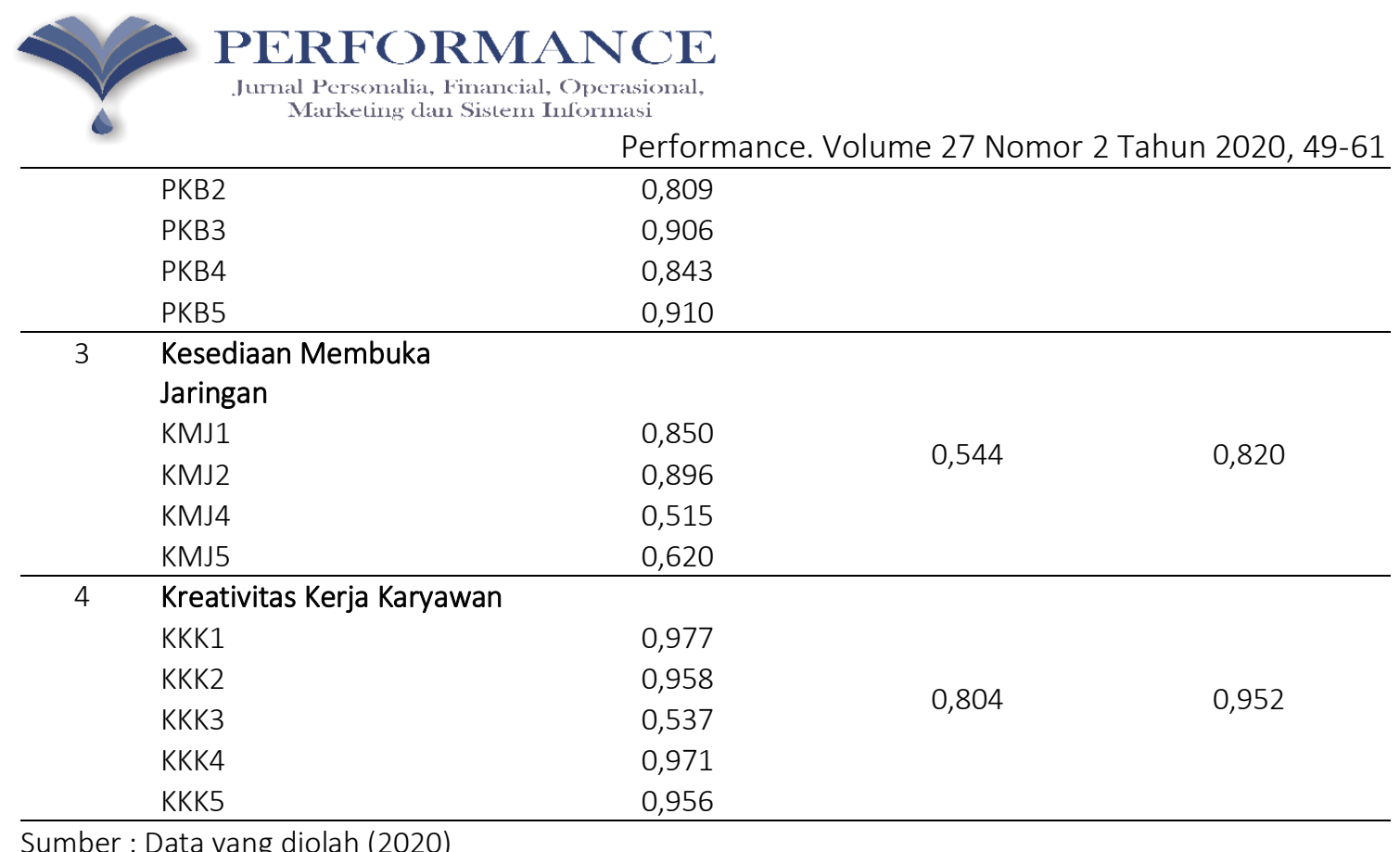

Berdasarkan data yang ditunjukkan pada Tabel 1 , nilai validitas konvergen budaya mencipta adalah 0,670 , sedangkan nilai validitas konvergen untuk perilaku kebebasan berkreasi, kesediaan membuka jaringan dan kreativitas kerja karyawan, secara berurutan, adalah 0,661, 0,554, dan 0,804 . Semua nilai validitas konvergen dari semua variabel berada diatas $\geq 0,50$, yang menandakan bahwa semua konstruk memiliki validitas yang baik. Selain itu, nilai keandalan budaya mencipta adalah 0,886, sedangkan nilai keandalan perilaku kebebasan berkreasi, kesediaan membuka jaringan dan kreativitas kerja karyawan, secara berurutan adalah 0,905, 0,820 , dan 0,952 . Semua nilai keandalan konstruk berada di atas 0,70 , yang berdasarkan ini, dapat dikatakan bahwa semua konstruk dapat diandalkan, atau bahwa setiap indikator variabel benarbenar menjelaskan keberadaan variabel.

\section{Pengujian Model Struktural (Inner Model)}

Setelah mengetahui semua konstruk memiliki validitas yang baik dan setiap indikator variabel benar-benar menjelaskan keberadaan variabel, tahap selanjutnya adalah menghitung besarnya nilai R -Square. Bedasarkan hasil perhitungan regresi menggunkan PLS dapat diketahui nilai R-Square sebagai berikut :

Tabel 2. Nilai R - Square

\begin{tabular}{ccc} 
Variabel & R-Square & R-Square Adjusted \\
\hline KKK & 0,708 & 0,698 \\
\hline KMJ & 0,533 & 0,528 \\
\hline PKB & 0,340 & 0,330 \\
\hline BM & - & -
\end{tabular}

Sumber : Data yang diolah (2020)

Tabel 2 atas menjelaskan bahwa nilai 0,340 untuk konstruk Perilaku Kebebasan Berkreasi (PKB) yang berarti bahwa Budaya Mencipta mampu menjelaskan varians PKB sebesar 34,00\%. Nilai R juga terdapat pada Kesediaan membuka jaringan (KMJ) yang dipengaruhi oleh PKB yaitu sebesar 0,533 dan Kreativitas Kerja Karyawan (KKK) yang dipengaruhi oleh BM, PKB dan KMJ yaitu sebesar 0,708. 
Performance. Volume 27 Nomor 2 Tahun 2020, 49-61

\section{Uji Hipotesis}

Pengujian model telah dilakukan, dengan menghasilkan penelitian yang menunjukan pengaruh antar variabel yang ditunjukan oleh nilai R-Square. Selanjutnya akan dilakukan uji hipotesis dengan hasil sebagai berikut :

Tabel 3. Path Coefficients

\begin{tabular}{lcccrrr}
\hline Variabel & $\begin{array}{c}\text { Original } \\
\text { Sampel (O) }\end{array}$ & $\begin{array}{c}\text { Sampel } \\
\text { Mean (M) }\end{array}$ & $\begin{array}{c}\text { Standar } \\
\text { Deviasi } \\
\text { (STDEV) }\end{array}$ & $\begin{array}{r}\text { T-Statistik } \\
\text { (O/STDEV) }\end{array}$ & P Values & Hasil \\
\hline BM -- > KKK & $-0,106$ & $-0,098$ & 0,055 & 1,925 & 0,055 & Ditolak \\
\hline BM - > PKB & 0,583 & 0,589 & 0,076 & 7,669 & 0,000 & Diterima \\
\hline KM -- > KKK & 0,561 & 0,559 & 0,113 & 4,959 & 0,000 & Diterima \\
\hline PKB -- > KKK & 0,409 & 0,402 & 0,103 & 3,965 & 0,000 & Diterima \\
\hline PKB -- > KMJ & 0,730 & 0,735 & 0,053 & 13,706 & 0,000 & Diterima \\
\hline
\end{tabular}

Sumber : Data yang diolah (2020)

Mengacu pada apa yang ditampilkan pada Tabel 3, ditunjukkan bahwa semua hipotesis, kecuali Hipotesis Satu, diterima. Hipotesis satu, yang menyatakan bahwa budaya mencipta dikaitkan dengan kreativitas kerja karyawan, ditolak. Hasil tersebut menjelaskan bahwa budaya mencipta yang ada di Industri Kreatif Provinsi Banten secara langsung belum mampu meningkatkan kreativitas kerja karyawan. Hipotesis dua, yang mengatakan bahwa budaya mencipta dikaitkan dengan perilaku kebebasan berkreasi, diterima dengan kategori sangat signifikan. Hasil tersebut menyatakan bahwa budaya mencipta yang diadakan organisasi telah mampu meningkatkan perilaku kebebasan berkreasi.

Hipotesis tiga yang menyatakan bahwa perilaku kebebasan berkreasi dikaitkan dengan kesediaan membuka jaringan juga diterima dan dalam kategori sangat signifikan. Hasil tersebut menyatakan bahwa perilaku kebebasan berkreasi yang dimiliki oleh karyawan telah mendorong untuk bersedia membuka jaringan dengan siapapun. Hipotesis empat mengatakan bahwa perilaku kebebasan berkreasi dikaitkan dengan kreativitas kerja karyawan diterima dengan kategori sangat signifikan. Hasil penelitian ini menjelaskan bahwa semakin tinggi perilaku kebebasan dalam berkreasi yang dimiliki karyawan, maka akan semakin meningkatkan kreativitas kerjanya. Hipotesis lima, yaitu kesediaan membuka jaringan dikaitkan dengan kreativitas kerja karyawan, diterima secara signifikan. Hasil tersebut menyatakan bahwa semakin bersedia karyawan dalam membuka jaringan, maka akan semakin kreatiflah karyawan dalam bekerja.

\section{Indirect Effect}

Uji indirect efect dilakukan untuk mengetahui apakah variabel intervening dalam penelitian ini yaitu perilaku kebebasan berkreasi dan kesedian membuka jaringan mempunyai peran sebagai variabel intervening atau tidak. Di bawah ini hasil dari perhitungan indirect efect :

Tabel 4. Indirect Effects

\begin{tabular}{lccccc}
\hline Variabel & $\begin{array}{c}\text { Original } \\
\text { Sampel } \\
(\mathbf{O})\end{array}$ & $\begin{array}{c}\text { Sampel } \\
\text { Mean (M) }\end{array}$ & $\begin{array}{c}\text { Standar } \\
\text { Deviasi } \\
\text { (STDEV) }\end{array}$ & $\begin{array}{c}\text { T-Statistik } \\
\text { (O/STDEV) }\end{array}$ & P Values \\
\hline PKB - > KMJ- > KKK & 0,410 & 0,412 & 0,097 & 4,215 & 0,000 \\
\hline BM - > PKB- >KMJ- > KKK & 0,239 & 0,244 & 0,070 & 3,410 & 0,001 \\
\hline BM- > PKB- > KKK & 0,238 & 0,236 & 0,065 & 3,643 & 0,000 \\
\hline BM - > PKB- >KMJ & 0,409 & 0,439 & 0,068 & 6,292 & 0,000 \\
\hline
\end{tabular}

Sumber : Data yang diolah (2020) 


\section{PERFORMANCE}

Jurnal Personalia, Financial, Operasional,

Marketing dau Sistem Informasi

Performance. Volume 27 Nomor 2 Tahun 2020, 49-61

Berdasarkan hasil perhitungan indirect effect pengaruh budaya mencipta terhadap kreativitas kerja karyawan melalui variabel intervening perilaku kebebasan berkreasi diperoleh hasil T-statistisk $(3,643) \geq 1,96$ dan nilai P-Value $\leq 0,000$, maka dapat disimpulkan bahwa perilaku kebebasan berkreasi dapat memediasi hubungan dorongan budaya mencipta terhadap kreativitas kerja karyawan.

Hasil perhitungan indirect effect pengaruh dorongan budaya mencipta terhadap kreativitas kerja karyawan melalui variabel intervening perilaku kebebasan berkreasi dan kesediaan membuka jaringan diperoleh hasil T-statistisk $(3,410) \geq 1,96$ dan nilai P-Value $\leq 0,001$, maka dapat disimpulkan bahwa perilaku kebebasan berkreasi dan kesediaan membuka jaringan dapat memediasi hubungan dorongan budaya mencipta terhadap kreativitas kerja karyawan.

Selanjutnya hasil perhitungan indirect effect pengaruh budaya mencipta terhadap kesediaan membuka jaringan melalui variabel intervening perilaku kebebasan berkreasi diperoleh hasil Tstatistisk $(6,292) \geq 1,96$ dan nilai P-Value $\leq 0,000$, maka dapat disimpulkan bahwa perilaku kebebasan berkreasi dapat memediasi hubungan budaya mencipta terhadap kesediaan membuka jaringan.

Kemudian Hasil perhitungan indirect effect pengaruh perilaku kebebasan berkreasi terhadap kreativitas kerja karyawan melalui variabel intervening kesediaan membuka jaringan diperoleh hasil T-statistisk $(4,215) \geq 1,96$ dan nilai $P$-Value $\leq 0,000$, maka dapat disimpulkan bahwa kesediaan membuka jaringan dapat memediasi hubungan perilaku kebebasan berkreasi terhadap kreativitas kerja karyawan.

\section{KESIMPULAN}

Hasil penelitian telah membuktikan bahwa perilaku kekebasan berkreasi dan kesediaan membuka jaringan memainkan peran penting dalam meningkatkan kreativitas kerja karyawan. Perilaku kebebasan berkreasi dan kesediaan membuka jaringan adalah jembatan untuk meningkatkan kreativitas kerja karyawan. Perilaku kebebasan berkreasi dikembangkan dari budaya mencipta, sedang kesediaan membuka jaringan dikembangkan dari budaya mencipta dan perilaku kebebasan berkreasi. Oleh karena itu, dapat dikatakan bahwa budaya mencipta akan mampu meningkatkan kreativitas kerja karyawan apabila dilakukan bersama dengan perilaku kebebsan berkreasi dan kesediaan membuka jaringan.

Selain itu, hasil penelitian telah memberikan kontribusi teoritis untuk pengembangan Teori Perilaku Organisasi. Penelitian ini juga berkontribusi pada pengembangan ilmu manajemen, terutama manajemen sumber daya manusia. Secara praktis, penelitian ini juga memberikan referensi untuk mengembangkan budaya organisasi dalam meningkatkan kreativitas kerja. Secara sosial, penelitian ini memiliki kontribusi besar kepada masyarakat, terutama akan berdampak pada peningkatan kreativitas kerja karyawan pada industry kreatif.

Penelitian ini memiliki dua keterbatasan. Keterbatasan pertama yaitu bahwa dari lima hipotesis yang diuji, hanya satu hipotesis yang ditolak, yaitu hipotesis satu yang menyatakan bahwa budaya mencipta tidak berkontribusi terhadap kreativitas kerja karyawan. Diperlukan verifikasi lebih lanjut untuk menggeneralisasi konsep ini. Batas lainnya adalah hanya tiga variabel anteseden dari kreativitas kerja karyawan yang diamati, dan tampaknya variabel-variabel lain masih dapat diselidiki. Keterlibatan variabel lain akan membuat penelitian selanjutnya tentang kreativitas kerja karyawan menjadi lebih deterministik.

\section{DAFTAR PUSTAKA}

Aktaş, E., Çiçek, I., \& Kiyak, M. (2011). The effect of organizational culture on organizational efficiency: The moderating role of organizational environment and CEO values. Procedia Social and Behavioral Sciences, 24, 1560-1573. 
Performance. Volume 27 Nomor 2 Tahun 2020, 49-61

https://doi.org/10.1016/j.sbspro.2011.09.092

Ali Taha, V., Sirková, M., \& Ferencová, M. (2016). Wpływ kultury organizacyjnej na kreatywność i innowacje. Polish Journal of Management Studies, 14(1), 7-17. https://doi.org/10.17512/pjms.2016.14.1.01

Asbari, M., Santoso, P. B., \& Purwanto, A. (2019). Pengaruh Kepemimpinan dan Budaya Organisasi Terhadap Perilaku Kerja Inovatif pada Industri 4.0. Jim Upb, 8(1), 7-15. https://doi.org/ttps://doi.org/10.33884/jimupb.v8i1.1562

Bai, Y., Lin, L., \& Li, P. P. (2016). How to enable employee creativity in a team context: A crosslevel mediating process of transformational leadership. Journal of Business Research, 69(9), 3240-3250. https://doi.org/10.1016/j.jbusres.2016.02.025

Bammens, Y. P. M. (2016). Employees' Innovative behavior in social context: A closer examination of the role of organizational care. Journal of Product Innovation Management, 33(3), 244259. https://doi.org/10.1111/jpim.12267

Brass, D. J., Galaskiewicz, J., Greve, H. R., \& Tsai, W. (2004). Taking stock of networks and organizations: A multilevel perspective. Academy of Management Journal, 47(6), 795-817. https://doi.org/10.2307/20159624

Cameron, Kim S. \& Quinn, R. E. (2006). Diagnosing And Changing Organizational Culture. Third Edition.

Çekmecelioğlu, H. G., \& Günsel, A. (2013). The Effects of Individual Creativity and Organizational Climate on Firm Innovativeness. Procedia - Social and Behavioral Sciences, 99(November 2013), 257-264. https://doi.org/10.1016/j.sbspro.2013.10.493

Chen, M. Y.-C., \& Lin, C. Y.-Y. (2010). Dose transformational leadership facilitate SBU innovation? The moderating roles of SBU culture and incentive compensation. 1-33. http://nccuir.lib.nccu.edu.tw/handle/140.119/41287

Dubkēvičs, L., Barbars, A., Pavlovska, V., \& Turlais, V. (2015). Evaluation of Intercultural Competency in Organizational Culture: Analysis of The Example of Latvia. Human Resources Management \& Ergonomics, IX(2/2015), 32-42.

Duran, P., Kammerlander, N., Van Essen, M., \& Zellweger, T. (2016). Doing more with less: Innovation input and output in family firms. Academy of Management Journal, 59(4), 12241264. https://doi.org/10.5465/amj.2014.0424

Fitriana, A. N. (2014). Pengembangan Industri Kreatif Di Kota Batu (Studi Tentang Industri Kreatif Sektor Kerajinan Di Kota Batu). Jurnal Administrasi Publik Mahasiswa Universitas Brawijaya, 2(2), 281-286.

Gilson, L. L., \& Litchfield, R. C. (2017). Idea collections: a link between creativity and innovation. Innovation: Management, Policy and Practice, 19(1), 80-85. https://doi.org/10.1080/14479338.2016.1270765

Gorondutse, A. H., \& Gawuna, M. S. (2017). Cost Leadership Strategy and Performance of Hotels. Journal of Applied Structural Equation Modeling, 1(1), 1-10. 
Jurnal Personalia, Financial, Operasional,

Marketing dau Sistem Informasi

Performance. Volume 27 Nomor 2 Tahun 2020, 49-61

https://doi.org/110.1111/jasem.12278080

Harris, S. G., \& Mossholder, K. W. (1996). The Affective Implications of Perceived Congruence with Culture Dimensions during Organizational Transformation. Journal of Management, 22(4), 527-547. https://doi.org/10.1177/014920639602200401

Hung, R. Y. Y., Lien, B. Y. H., Yang, B., Wu, C. M., \& Kuo, Y. M. (2011). Impact of TQM and organizational learning on innovation performance in the high-tech industry. International Business Review, 20(2), 213-225. https://doi.org/10.1016/j.ibusrev.2010.07.001

Jung, D. I., Chow, C., \& Wu, A. (2003). The role of transformational leadership in enhancing organizational innovation: Hypotheses and some preliminary findings. Leadership Quarterly, 14(4-5), 525-544. https://doi.org/10.1016/S1048-9843(03)00050-X

Karlsson, C. (2011). Clusters, networks and creativity. Handbook of Creative Cities, 235, 85-114. https://doi.org/10.4337/9780857936394.00010

Khurosani, A. (2013). Adhocracy Culture Support and Leader's Working Creativity. International Journal of Social Science and Humanity, 3(4), 411-415. https://doi.org/10.7763/ijssh.2013.v3.272

Linehan, M., \& Scullion, H. (2008). The development of female global managers: The role of mentoring and networking. Journal of Business Ethics, 83(1), 29-40. https://doi.org/10.1007/s10551-007-9657-0

McLean, L. D. (2005). Organizational Culture's Influence on Creativity and Innovation: A Review of the Literature and Implications for Human Resource Development. Advances in Developing Human Resources, 7(2), 226-246. https://doi.org/10.1177/1523422305274528

Mobarakeh, N. S. (2011). The relation between the organizational culture and creativity of managers and experts of Khuzestan physical education organization. Procedia-Social and Behavioral Sciences, 15, 3648-3650. https://doi.org/10.1016/j.sbspro.2011.04.350

Ogbeibu, S., Senadjki, A., \& Gaskin, J. (2018). The moderating effect of benevolence on the impact of organisational culture on employee creativity. Journal of Business Research, 90(May), 334-346. https://doi.org/10.1016/j.jbusres.2018.05.032

Peranginangin, J., \& Kusumawardhani, A. (2018). Islamic relationship value, adaptive selling, and, relationship quality effect to salesforce performance. Journal of Business and Retail Management Research, 12(4), 37-42. https://doi.org/10.24052/jbrmr/v12is04/art-04

Qi, L., Liu, B., Wei, X., \& Hu, Y. (2019). Impact of inclusive leadership on employee innovative behavior: Perceived organizational support as a mediator. PLOS ONE, 14(2), 1-14. https://doi.org/10.1371/journal.pone.0212091

Rashid, R. A., \& Rahman, M. F. A. (2014). Social networking sites for online mentoring and creativity enhancement. International Journal of Technology Enhanced Learning, 6(1), 3445. https://doi.org/10.1504/IJTEL.2014.060024

Schein, E. H., \& Night, T. (n.d.). Organizational Culture \& Leadership by. 1-19. 
Jurnal Personalia, Financial, Operasional,

Marketing dam Sistem Informasi

Performance. Volume 27 Nomor 2 Tahun 2020, 49-61

Sigala, M., \& Chalkiti, K. (2015). Knowledge management, social media and employee creativity. International Journal of Hospitality Management, 45, 44-58. https://doi.org/10.1016/j.ijhm.2014.11.003

Smith, A. D., \& Rupp, W. T. (2002). Communication and loyalty among knowledge workers: A resource of the firm theory view. Journal of Knowledge Management, 6(3), 250-261. https://doi.org/10.1108/13673270210434359

Tabachnick, B. G. \& Fidell, L. S. (2013). Using Multivariate Statistics, United State of America, Pearson Education.

Tierney, P., Farmer, S. M., \& Farmer, S. M. (2014). Creative Self-Efficacy : Its Potential Antecedents and Relationship To Creative Performance. 45(6), 1137-1148. https://doi.org/10.2307/3069429

Uzzi, B., Amarai, L. A. N., \& Reed-tsochas, F. (2007). Science Research : a Review. European Management Review, 77-91.

Villar, L., Dayan, G. H., Arredondo-García, J. L., Rivera, D. M., Cunha, R., Deseda, C., Reynales, H., Costa, M. S., Morales-Ramírez, J. O., Carrasquilla, G., Rey, L. C., Dietze, R., Luz, K., Rivas, E., Montoya, M. C. M., Supelano, M. C., Zambrano, B., Langevin, E., Boaz, M., ... Noriega, F. (2014). Efficacy of a Tetravalent Dengue Vaccine in Children in Latin America. New England Journal of Medicine, 372(2), 141103114505002. https://doi.org/10.1056/NEJMoa1411037

Yuan, F., \& Woodman, R. W. (2010). Innovative behavior in the workplace: The role of performance and image outcome expectations. Academy of Management Journal, 53(2), 323-342. https://doi.org/10.5465/amj.2010.49388995

Zhang, X., \& Bartol, K. M. (2010). Linking empowering leadership and employee creativity: the influence of psychological empowerment, intrinsic motivation, and creative process management. Academy of Management Journal, 53(1), 107-128. https://doi.org/10.5465/AMJ.2010.48037118

Zhiming, Z., Tao, C., Hailiang, C., \& Qianyi, D. (2013). Journal of business management studies. Journal of Business Management \& Economics, 1(1), 23-30. www.innovativejournal.info 